\section{The Estimated Impact of Drug Importation, Mandatory Mail Service, and Medicaid Fee Reduction on Community Pharmacies in Michigan}

One common characteristic of the trend toward increased use of mail-service pharmacy services and personal importation of pharmaceuticals is the shift of prescription sales from Michigan pharmacies to out-of-state pharmacies. The absolute and relative economic impact of 3 developments affecting Michigan community pharmacists are of interest: (1) the adoption of mandatory mail-service requirements in pharmacy benefit programs of Michigan employers, (2) the hypothetical legalization of consumer importation of pharmaceuticals including crossborder shopping, and (3) the recent Michigan Medicaid pharmacy dispensing fee reduction.

A hypothetical community pharmacy unit was constructed using aggregate statistics to investigate the estimated outcomes of these 3 policy changes. Estimates of the magnitude of mandatory mail-service pharmacy and drug importation were developed from data from the Congressional Budget Office (CBO) and from a 2003 report from Milliman USA (consultants and actuaries) funded by the Pharmaceutical Care Management Association (PCMA). These estimates were applied to the hypothetical community pharmacy unit and to the total Michigan community pharmacy market, yielding macroeconomic measures of lost sales, profits, and salaries.

Assuming importation of pharmaceuticals is legalized, the total pharmacy and manufacturer loss is 1,778 jobs in Michigan, and lost sales to out-of-state and out-of-country pharmacies is $\$ 450$ million. Mandatory mail-service pharmacy shifts $\$ 750$ million to out-of-state pharmacies, and the equivalent of $\$ 81$ million is lost in annual employee salaries in Michigan. The Medicaid fee reduction reduced community pharmacy revenue by $\$ 16$ million. The 3 policy developments combined result in total community pharmacy lost sales of $\$ 1.216$ billion (20\% of a $\$ 6$ billion market) and $\$ 280$ million in lost payroll and net profits to owners of Michigan pharmacies. Therefore, mandatory mail service in employer health plans had the most significant impact of the 3 policy changes, accounting for $62 \%$ of the total financial impact. Unlike the broad effects of drug importation on drug manufacturers and pharmacy wholesalers as well as community pharmacies, mandatory mail service primarily affects Michigan community pharmacies. The reduction in the Medicaid dispensing fee impacted the profit margin for pharmacy owners but had little if any impact on salaries.

The background for this analysis includes a Michigan community pharmacy market that faced the prospect of significant private policy changes by major employers mandating mailservice pharmacy services and the state of Michigan reducing the Medicaid dispensing fee by $34 \%$, from $\$ 3.77$ to $\$ 2.50$ begin-

Note: A commentary on the subject of this article appears on pages 164-67 of this issue.

\section{TABLE 1 Assumptions Employed in} These Economic Estimates*

\begin{tabular}{l|r}
\hline $\begin{array}{l}\text { Average number of Rxs dispensed per year per pharmacy } \\
\text { (in 2003)* }\end{array}$ & 56,399 \\
\hline Average sales price per Rx* & $\$ 51.44$ \\
\hline $\begin{array}{l}\text { Estimated annual prescription (Rx) sales }[\$ 2,606,479 *] \\
\text { per pharmacy }\end{array}$ & $\$ 3,000,000$ \\
\hline $\begin{array}{l}\text { Estimated cost of goods sold }(77.0 \%)[\$ 2,009,161 \text { or } \\
77.1 \%]^{*} \text { per pharmacy }\end{array}$ & $\$ 2,310,000$ \\
\hline Gross margin $\left(23.0 \%\right.$ vs. $\left.22.9 \%[597,318]^{*}\right)$ per pharmacy & $\$ 690,000$ \\
\hline $4.0 \%[\$ 114,319,4.4 \%]^{*}$ per pharmacy & $\$ 120,000$ \\
\hline Number of Michigan community pharmacies & 2,000 \\
\hline $\begin{array}{l}\text { (000)-\$6 billion in annual Michigan community pharmacy } \\
\text { Rx sales }\end{array}$ & $\$ 6,000,000$ \\
\hline Number of Michigan residents ${ }^{9}$ & $10,002,379$ \\
\hline $\begin{array}{l}\text { Number of Michigan residents subject to employer } \\
\text { health plan mandates }\end{array}$ & $5,000,000$ \\
\hline Number of mail-service Rxs per year per affected beneficiary $\dagger$ & 1.0 \\
\hline Number of community pharmacy mail-service Rx equivalents $\dagger$ & 3.0 \\
\hline
\end{tabular}

* These are median values in this table except for the average number of Rxs and the average price per $R x$. The average number of $R x$ s and the average price per $R x$ and all data presented in brackets [] were obtained from the National Community Pharmacists Association, 2004 NCPA-Pfizer Digest, October 2004, for data reported for 2003.

+ Derived from the Milliman USA report prepared for the Pharmaceutical Care Management Association. ${ }^{5}$

$R x=$ prescription .

ning January 1, 2004. Along with these 2 proposed policy changes, there was significant interest in legalizing importation of pharmaceuticals because personal importation also shifts prescription sales to out-of-state pharmacies. These 3 public and private policy developments provided an opportunity to examine the economic impact on Michigan community pharmacies. The objective of the present analysis was to measure the collective and relative economic impact of the shift to employermandated mail-service pharmacy services, personal importation of pharmaceuticals, and the Medicaid pharmacy dispensing fee reduction. The economic impacts are estimated per pharmacy and extrapolated for the entire state of Michigan.

The pharmacy unit used for illustrations represents an amalgamation of all Michigan community pharmacies. Using published values for total and median prescription drug sales from the 2004 NCPA-Pfizer Digest, ${ }^{1}$ a hypothetical prescription drug pharmacy unit was constructed. It was assumed that Michigan residents consumed $\$ 6$ billion in prescription drugs in 2003, based upon published estimates of expenditures in the range of $\$ 5.9$ billion $^{2}$ to $\$ 8.4$ billion. $^{3}$ The number of community pharmacy licenses in Michigan exceeds 2,000, ${ }^{4}$ but there are multiple licenses for the same location in some cases. For the 
purpose of convenience and simplification, 2,000 pharmacies are accepted as the approximate number of chain and independent pharmacies in Michigan. The 2004 Digest shows a national average of $\$ 2.9$ million in prescription drug sales in 2003, and the number of full-time equivalent (FTE) employees per pharmacy was 9.5, including 1.4 employee pharmacists plus 1.1 owner pharmacists, bringing the total to 10.5 FTE pharmacy personnel per pharmacy. Chain and food-market pharmacy statistics vary a bit, but assuming 2,000 Michigan pharmacies each filling 56,000 prescriptions annually and averaging \$3 million in prescription drug sales per unit makes it easier to illustrate the impact on a typical Michigan community pharmacy unit. The assumptions are forced to fit a $\$ 6$ billion Michigan pharmaceuticals market. The assumptions used in these economic estimates are shown in Table 1, including the median prescription sales statistics for a single community pharmacy.

\section{Policy Change \#1: Employer-Mandated Mail-Service Pharmacy}

At the time of these analyses, Michigan pharmacies were prohibited from dispensing mail-service prescriptions. Consequently mandatory mail-service requirements in employee drug benefit plans resulted in prescriptions being shifted to out-of-state pharmacies. Mandatory mail-service volume was extrapolated from the Milliman USA study commissioned by PCMA to study the impact of Michigan House Bill $4987 .{ }^{5}$ HB 4987 was advanced in 2004 as "any-willing-provider" legislation and would have reduced the ability of health plan sponsors to discriminate between mail-service and community pharmacy. ${ }^{6}$ The objective of this bill was to require drug benefit programs to allow community pharmacies to dispense quantities similar to those dispensed by mail-service pharmacies. The conclusion from the Milliman-PCMA study was that Michigan employers would pay $\$ 30$ (7.9\%) more per capita in 2004 dollars if community pharmacies were provided access to the share of the market being channeled to mail-service pharmacies, derived $86 \%$ from $\$ 26$ per capita increased cost due to the loss of discount pricing leverage for pharmacy benefit managers (PBMs) and $14 \%$ ( $\$ 4$ per capita) from the difference in community versus mail-service pharmacy pricing.

Assuming that each mail-service prescription (90-day supply) is roughly equivalent to 3 community pharmacy prescriptions (30-day supply each), a simple calculation using 5 million eligible members each receiving 1 mail-service prescription represents 15 million prescriptions per year lost from community pharmacies. If the average community pharmacy prescription price is about $\$ 50$, the result is $\$ 750$ million in lost sales (12.5\%) by Michigan pharmacies.

The 2.37 million affected persons in Michigan in the Milliman-PCMA analysis resulted from the exclusion of approximately $45 \%$ of the Michigan population, including the Blues, self-funded plans, cash (self) pay, and Medicaid consumers. In this Milliman-PCMA analysis, there were 3 primary assumptions that contributed to the estimated $\$ 30$ per capita savings ( $\$ 71$ million divided by 2.37 million persons): (a) $\$ 10$ savings (from the elimination of 2 community pharmacy dispensing fees for each mail-service prescription, (b) a larger discount off average wholesale price (AWP), and (c) implied impact from rebates from mail-service pharmacies shared with drug plan sponsors.

The Milliman-PCMA report does not specify the details for the derivation of the $\$ 30$ per-capita savings, and this report was not published in a peer-reviewed journal. In making the unsupported assumptions, the authors included caveats such as "actuarial modeling is not a precise science and involves judgment- based estimates." Regardless of the caveats regarding the unsupported assumptions, the conclusions, as is often the case, were embraced by many Michigan legislators, employer groups, and the media. ${ }^{\top}$ If this statistic is extrapolated to half the Michigan population, or 5 million lives, the results would suggest $\$ 145$ million in annual "savings." the present analysis assumes that employers, in addition to the 2.37 million covered population identified in the MillimanPMCA study, would adopt or have adopted similar policies requiring mandatory mail-service pharmacy dispensing.

\section{Policy Change \#2: Legalization of Drug Importation}

Of the 3 policy developments examined, drug importation assumed that there would be enabling federal legislation. The current social/political climate bodes well for the advancement of importation legislation for several reasons. In this author's opinion, there is spillover from the corporate scandals in the tobacco, energy, and telecommunication industries for investors, voters, and consumers, contributing to an anticorporation sentiment. Any hint of corporate deception or ill-gotten profits is an opportunity for front-page journalism.

Additionally, those responsible for managing health care expenditures have little enthusiasm for more expensive pharmaceutical innovations. Given the anticipated $10.7 \%$ annual expenditure growth for pharmaceutical expenditures for the time period 2004-2013,9 expensive innovations may be especially unwelcome. Most observers don't believe that spending on pharmaceuticals and pharmaceutical care is offset by reductions in other health care expenditures. The importation debate has also sometimes characterized the U.S. Food and Drug Administration (FDA) as the vanguard of the pharmaceutical industry.

Drug importation has evoked concerns about product integrity and patient safety, but there are also cost considerations. Potential savings from drug importation are undermined by the availability of cheaper generic drugs in the United States compared with Canada ${ }^{10}$ and the fact that biologicals tend to be excluded from proposed legislation that would permit drug importation. These factors are joined by changes in the U.S. Department of Health and Human Services (HHS) and FDA leadership and recent public attention focused on pharmaceutical product recalls and safety concerns for commonly used drugs 
such as Vioxx. ${ }^{11}$ One consequence is an increased enthusiasm for greater drug safety surveillance, probably at the expense of future speedy drug approvals. It is possible that increased budget allocation for the FDA would include funding for surveillance, perhaps making more likely legalization of drug importation (with FDA surveillance).

In the political mix is the question of why the United States should bear the cost burden of global pharmaceutical research and development $(R \& D)$ in a global pharmaceutical market, perhaps increasing the probability of ultimate legislative success for drug importation. The HHS Task Force on Drug Importation ${ }^{12}$ estimates the 2003 import volume at $\$ 1.4$ billion. This represents $0.6 \%$ of the U.S. $\$ 221.4$ billion sales reported by IMS Health, which includes some over-the-counter sales. ${ }^{13}$ Legalization could have at least a 10-fold increase on drug importation. Convenient access, price differentials, and well-integrated economies, especially in the geographic areas of Michigan with the densest populations, are 3 factors contributing to the higher cross-border shopping in Michigan. ${ }^{14}$ Markets outside the United States experience volume slippage due to parallel imports-the amount of products imported to a country that is not consumed in that country. Based on estimates of slippage experienced in other countries, the U.S. Congressional Budget Office (CBO) estimates that the import volume of legalized importation would be $10 \%$ to $15 \%$ of the U.S. market if drug importation is legalized, ${ }^{15}$ increasing the volume of imported drugs. ${ }^{14}$

Since the $\mathrm{CBO}$ report, storefront pharmacies have been established to facilitate importation ${ }^{12}$ so the higher end of the range was used. I estimate $7.5 \%$ of total prescription volume in Michigan to be the current level of personal importation by Internet, mail service, storefront Canadian pharmacies, and cross-border shopping. The remaining $7.5 \%$ are excluded from this analysis because commercial importation would be transmitted through wholesalers and community pharmacies and would not result in lost prescription sales. Senate Bill (SB) $2328^{16}$ called for both commercial and personal importation, and $7.5 \%$ represents half the volume assumed by the $\mathrm{CBO}$ in concluding that a $\$ 4$ billion expenditure reduction, approximately $1 \%$ of expected Medicare expenditures, would be realized over the next 10 years. Legalizing importation will be a stimulus to Internet pharmacy sales if consumers interpret legalization as government-assured product integrity. The hypothetical impact of legalized importation is a little more than half the impact of mail service, $7.5 \%$ versus $12.5 \%$, or about $\$ 450$ million. The impact on profits and employee payroll on community pharmacies is illustrated later, along with impact on manufacturing pharmacy since both are affected.
Drug reimportation and importation have grown gradually over several years, and the effects are not immediately visible to community pharmacists. Consequently, the potential business impact on community pharmacy is not as obvious as mandatory mail service or a service fee reduction from a payer (Medicaid). Second, drug importation impacts both community and manufacturing pharmacy, but some may erroneously see drug importation as primarily a pharmaceutical industry issue.

\section{Estimating the Impact of the Reduction in Medicaid Dispense Fee}

The impact of the Medicaid fee reduction is approximately $\$ 8,000$ per Michigan pharmacy, but, of course, the financial impact is not uniform across pharmacy types or individual pharmacies because of differences in the relative proportion of total pharmacy sales volume accounted for by Medicaid (i.e., payer mix). This estimate is the result of dividing the number of Medicaid prescription in 2003 by the estimated 2,000 licensed Michigan pharmacies and multiplying this number times the $\$ 1.27$ dispensing fee reduction (34\%) from $\$ 3.77$ to $\$ 2.50$. Only fee-for-service Medicaid prescriptions are used in the estimate. Unlike mail-service pharmacy and personal drug importation, the Medicaid fee reduction does not result in significantly lower pharmacy sales- $\$ 8,000$ (1.2\%) of $\$ 608,000$ total lost sales (Table 2).

The impact of the Medicaid fee reduction appears small in relation to mandatory mail service because the workload and investment does not change. Pharmaceutical products must be purchased and dispensed but at a lower profit. Assuming pharmacies realize a $4 \%$ net profit (Table 1 ), the $\$ 8,000$ loss of dispense 


\begin{tabular}{l|c|c|c|c}
\hline TABLE 3 & $\begin{array}{l}\text { Aggregate Michigan Pharmacy Sales } \\
\text { and Profit Losses (\$ Millions) }\end{array}$ \\
\hline & $\begin{array}{c}\text { Mandatory } \\
\text { Mail } \\
\text { Service (\$) }\end{array}$ & $\begin{array}{c}\text { Importation } \\
\text { (\$) }\end{array}$ & $\begin{array}{c}\text { Medicaid } \\
\text { Fee Cut (\$) }\end{array}$ & Total (\$) \\
\hline Effect of policy* & $\begin{array}{c}6,000 \text { million } \\
\text { x } 12.5 \%\end{array}$ & $\begin{array}{c}6,000 \text { million } \\
\text { x 7.5\% }\end{array}$ & - & - \\
\hline $\begin{array}{l}\text { Michigan Rx } \\
\text { sales loss }\end{array}$ & 750 & 450 & 16 & 1,216 \\
\hline $\begin{array}{l}\text { Lost Michigan Rx } \\
\text { cost of goods (77\%) }\end{array}$ & 577.5 & 346.5 & 0 & - \\
\hline $\begin{array}{l}\text { Lost Michigan } \\
\text { gross margin (23\%) }\end{array}$ & 172.5 & 103.5 & 16 & - \\
\hline $\begin{array}{l}\text { Lost Michigan } \\
\text { Rx net profits (4\%) }\end{array}$ & 30 & 18 & 16 & 64 \\
\hline
\end{tabular}

* $\$ 6,000$ million is derived from $\$ 3$ million per pharmacy $\times 2,000$ community pharmacies.

$\uparrow$ National Community Pharmacists Association, 2004 NCPA-Pfizer Digest, October 2004, for 2003 community pharmacy data. ${ }^{1}$

fee revenue would require a $\$ 200,000$ increase in pharmacy sales revenue to offset the impact on pharmacy net profit.

\section{Estimating the Relative Business and Social Impact of the 3 Policy Changes}

In Table 2, the values are presented for the hypothetical individual pharmacy unit created earlier. The impact of the mandatory mail-service is to reduce community pharmacy sales by $12.5 \%$ or $\$ 375,000$ ( $\$ 3$ million $\times 0.125$ ), and corresponding adjustments are made to all other values, using the same $12.5 \%$ multiplier. The importation policy reduces annual sales $7.5 \%$ or $\$ 225,000$, and the Medicaid fee reduction affects only the net profit, reducing the hypothetical $\$ 120,000$ by $\$ 8,000$ but leaving other values essentially the same, with the $\$ 8,000$ reduction being constant. For example, under the mail-service policy change, annual sales are reduced by $\$ 375,000$, gross margin is reduced by $\$ 86,250$, and net profit is reduced by $\$ 15,000$.

The bulk ( $\$ 924$ million or $76 \%$ ) of the aggregate $\$ 1.216$ billion annual lost sales (Table 3 ) is the cost of goods sold (COGS) for prescriptions not dispensed from Michigan pharmacies. More significant to the Michigan economy are the lost salaries and net profits that would have been generated and spent again in the community economy.

The impact on prescription sales per community pharmacy was estimated to be $12.5 \%$ for mandatory mail service, $7.5 \%$ for personal importation, and $\$ 8,000(0.27 \%)$ for the $34 \%$ reduction in the Medicaid dispense fee. The hypothetical benchmark pharmacy with $\$ 3$ million in annual prescription drug sales has 10.5 FTEs and $4 \%$ net profit. The per-pharmacy impact on net profits from fee adjustment $(-\$ 8,000)$ is approximately equal to the estimated impact of personal importation $(-\$ 9,000)$ but considerably less than the impact of mandatory mail service $(-\$ 15,000)$.
In Table 4, the losses in sales and profits are restated at both the individual pharmacy and aggregate level for the state of Michigan.

The lost Michigan payroll is estimated by using Digest median values to calculate revenue lost for salaries by multiplying the lost sales times $9 \%$, which is the median proportion of sales dedicated to salaries. Consequently, at the pharmacy level, the $\$ 375,000$ lost sales attributable to mandatory mail service results in a loss of $\$ 33,750$ ( $\$ 375,000 \times 0.09)$. Further, dividing the lost salary revenue by the median expenses per employee$\$ 36,000$-results in 0.94 FTE lost per pharmacy. As illustrated in Table 5, extending this loss to 2,000 pharmacies results in a loss of 1,880 FTEs in Michigan. This analysis is extended to losses attributable to personal importation if and when it is legalized. The presumed across-the-board reduction proportional to decreased revenue is a general assumption applied to the aggregate. Individual pharmacies may or may not reduce personnel proportional to the decreased revenue.

Unlike mandatory mail service, personal importation, if legalized, could result in an additional loss of pharmaceutical $R \& D$ and manufacturing jobs. The U.S. Bureau of Labor Statistics (Wage and Salary Distribution by IndustryMichigan) reported a total of 8,700 Michigan pharmaceutical manufacturing jobs in 2000 . The $12.5 \%$ reduction in pharmaceuticals sold would result in a corresponding loss of manufacturing jobs. However, lost sales to Michigan pharmacies are offset by increased sales to Canadian pharmacies albeit at lower prices. The lost COGS are reduced by $50 \%(15 \% \div 2=7.5 \%)$ and the loss of manufacturing jobs is $653(8,700 \times 0.075)$.

The direct economic effect of mandatory mail service, importation, and the Medicaid fee cut is the loss of 3,658 jobs (1,880 due to mail service, 1,125 due to importation in community pharmacies, and 653 due to importation for pharmaceutical manufacturers) and $\$ 306$ million, including the corresponding reduction in employee payroll, employer payroll, and net profits to the community businesses (Table 6). This exercise examines the negative impact on the Michigan community pharmacies, but Michigan pharmaceutical manufacturers are also "losers."

"Savings" from mandatory mail service is $\$ 145$ million if the Milliman-PCMA projected savings are extrapolated to half the Michigan population (Table 6). The $\$ 180$ million in savings to consumers from drug importation assumes a $40 \%$ price differential. A comparison using top-selling brand-name products representing nearly 45\% of the U.S. market in 2002 showed that Canadian prices were approximately $60 \%$ of the U.S. selling price in 2003. ${ }^{12}$

Foremost among the limitations of this analysis is the estimate of cost savings contained in the Milliman-PCMA report. This report estimated that Michigan employer-sponsored, non-Blues Association, non-self-funded prescription drug benefit plans using PBM services would spend $\$ 379$ per capita in 2004 for drug benefit coverage, before member cost-share. The 


\begin{tabular}{|c|c|c|c|}
\hline & $\begin{array}{l}\text { Mandatory Mail } \\
\text { Service@ } 12.5 \%\end{array}$ & $\begin{array}{l}\text { Importation at } 7.5 \% \\
\text { (Pharmacy and } \\
\text { Manufacturing) }\end{array}$ & $\begin{array}{c}\text { Importation @ 7.5\% } \\
\text { (Pharmacy Only) }\end{array}$ \\
\hline Individual pharmacy sales loss & $-\$ 375,000$ & $-\$ 225,000$ & $-\$ 225,000$ \\
\hline Lost employee payroll (9\% of sales) & $-\$ 33,750$ & $-\$ 20,250$ & $-\$ 20,250$ \\
\hline FTE job loss per pharmacy* & -0.94 & -0.56 & -0.56 \\
\hline Statewide loss of jobs for 2,000 pharmacies & $-1,880$ & $-1,125$ & $-1,125$ \\
\hline Owner profit loss (8.1\% of lost sales) & $-\$ 30,375$ & $-\$ 18,225$ & $-\$ 18,225$ \\
\hline Aggregate lost Rx sales & $-\$ 750$ million & -\$450 million & -\$450 million \\
\hline Lost Michigan COGS at $77 \%$ of lost Rx sales & $-\$ 577.5$ million & $-\$ 346.5$ million & $-\$ 346 / 5$ million \\
\hline Manufacturer FTE job loss $\dagger$ & - & -652.5 & - \\
\hline Lost manufacturing payroll in Michigan $\ddagger$ & - & $-\$ 58,725,000$ & - \\
\hline Manufacturing and pharmacy employee loss $(652.5+1,125)$ & - & $-1,778$ & - \\
\hline $8.1 \%$ owner discretionary profits§ & $-\$ 60.75$ million & $-\$ 36.45$ million & $-\$ 36.45$ million \\
\hline Aggregate lost Michigan pharmacy payroll ॥ & -\$67.5 million & -\$40.5 million & -\$40.5 million \\
\hline Employee and owner loss (2 rows above) & $-\$ 128.25$ million & $-\$ 135.675$ million & $-\$ 76.95$ million \\
\hline \multicolumn{4}{|l|}{$\begin{array}{l}\text { * Lost employee payroll divided by average annual salary of } \$ 36,000 \text {. } \\
\text { \$8,700 manufacturing jobs (extracted from the U.S Bureau of Labor Statist } \\
\text { codes, including medicinal and botanical manufacturing, pharmaceutical pr } \\
\text { multiplied by } 0.075 \% \text { reduction. } \\
\text { \$ Lost FTE jobs (652.5) multiplied by annual estimated salary of } \$ 90,000 \text {. } \\
\S 8.1 \% \text { multiplied by aggregate lost } R x \text { sales. } \\
\text { II 9\% of aggregate lost Rx sales. } \\
\text { COGS=cost of goods sold; FTE=full-time equivalent; Rx=prescription. }\end{array}$} \\
\hline
\end{tabular}

Milliman-PCMA report estimated that eliminating the ability of PBM mail-service pharmacies to provide financial incentives for members to use mail service and permitting community pharmacies to dispense mail-service quantities (e.g., 90-day supply) would result in $\$ 30$ per capita higher costs in 2004 , comprising $\$ 26$ per capita (86\%) of lost price leverage that PBMs have with community pharmacies and $\$ 4(14 \%)$ from "disallowing differentiated mail-service pricing and removing enrollees' financial incentive for using mail order." Neither of these estimates are developed or supported in the Milliman-PCMA report, and others have found that mail-service pharmacy can cost more than community pharmacy dispensing after consideration of the financial incentive provided to drug plan members to use mail service (e.g., only 1 or 2 copayments for a 90-day supply). A recent analysis by Carroll et al. found $7.0 \%$ higher cost for mail-service pharmacy compared with community pharmacy for drug plan sponsors after considering the effect of lower copayments for mail service. ${ }^{17}$

Second, there was no attempt in this analysis to assess the costs associated with inconvenience or disruption from forcing drug benefit plan members to use mail service. There was also no attempt to estimate any quality-of-care outcomes that might arise from current policy versus proposed policy.

Third, a sophisticated assessment of the economic impact should include the secondary (induced) effects such as lost jobs, supplier business, feeder industries, etc. However, to simplify this analysis, none of the indirect and induced effects included in usual and customary economic impact analyses are applied. The data presented in tables 4 through 6 assume 653 manufacturer jobs lost and $\$ 58.7$ million lost in manufacturer payroll. These are conservative estimates in the context of economic impact studies. Professor Dean Smith, at the University of Michigan, was commissioned by drug manufacturer Pfizer to estimate the impact of importation on the Michigan economy. Employing assumptions used by economists, there is a 6.2 multiplier effect for each industry job lost. In an unpublished analysis, Smith estimated that 74,000 Michigan lost jobs are industry-related, after applying this multiplier effect on 12,000 jobs compiled by him using 2003 data from the Michigan Economic Development Corporation. ${ }^{18}$ His estimates for the 2005 economic impact of importation in Michigan include $\$ 987$ million in lost payroll in 2005. Smith's analysis produces a larger financial impact because of the assumption of the substantial negative effect on $R \& D$ investment because of the role the U.S. market has traditionally played in funding a disproportionate share of global pharmaceutical research. Comparing Smith's $\$ 987$ million with the $\$ 58.7$ million in this analysis illustrates the relationship of direct and induced effects. 


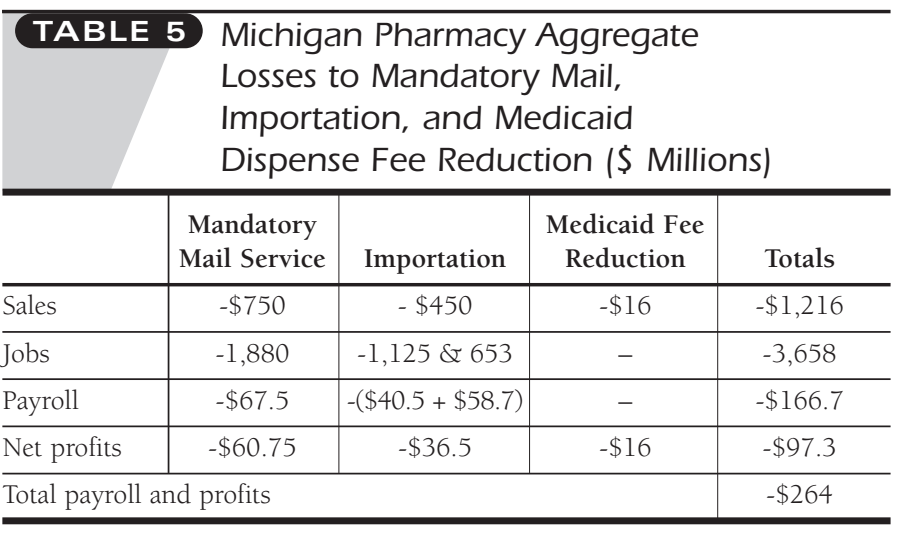

\begin{tabular}{|c|c|c|c|c|}
\hline & $\begin{array}{c}\text { Savings } \\
\text { in Millions (\$) }\end{array}$ & $\begin{array}{c}\text { Losses* } \\
\text { in Millions (\$) }\end{array}$ & Winners & Losers \\
\hline $\begin{array}{l}\text { Mandatory } \\
\text { mail }\end{array}$ & $145 \dagger$ & (154) & $\begin{array}{c}\text { Nonpharmacy } \\
\text { employers }\end{array}$ & $\begin{array}{c}\text { Local } \\
\text { pharmacy } \\
\text { employees } \\
\text { and owners }\end{array}$ \\
\hline Importation & 180丮 & (136) & $\begin{array}{l}\text { Payers and } \\
\text { consumers }\end{array}$ & $\begin{array}{l}\text { Manufacturers } \\
\text { and local } \\
\text { pharmacies }\end{array}$ \\
\hline $\begin{array}{l}\text { Medicaid fee } \\
\text { reduction }\end{array}$ & 16 & (16) & $\begin{array}{c}\text { State of } \\
\text { Michigan }\end{array}$ & $\begin{array}{c}\text { Owner } \\
\text { pharmacists }\end{array}$ \\
\hline Total & 341 & (306) & & \\
\hline
\end{tabular}

* See Table 3 .

$\dagger$ Milliman-PCMA report: $\$ 71$ million extrapolated to half the Michigan population.

$\$ 40 \%$ price differential on $\$ 450$ million in diverted U.S. sales.

These estimates rely exclusively on statistics reported by others, and the author had to make reasoned assumptions. Further, the impact of personal drug importation could be exaggerated if final regulations nudge consumers toward commercial importation through existing distribution channels. However, given 4 gateways to personal drug importation and the probable costs of commercial importation, it is reasonable to assume that the volume of personal importation will be significant. These estimates are limited to the single state of Michigan, which prohibits mail-service pharmacies from having dispensing operations inside the state. Obviously, those states with mailservice pharmacies servicing Michigan will benefit from the shift. The negative impacts on state tax revenues are not included.

This exercise may help highlight some of the factors that determine the relative importance of alternate policy developments on the economy of the state and various stakeholders, including individual community pharmacies, pharmacy owners, and consumers. The Medicaid dispensing fee reduction has a small effect on community pharmacy sales relative to the legalization of prescription drug importation and an even smaller effect compared with mandatory mail-service requirements in drug benefit plans. However, the effect on community pharmacy net profit from the Medicaid fee reduction is approximately equivalent to drug importation and about half the effect of mandatory mail service.

Patrick L. McKercher, PhD Senior Policy Fellow

Center for Drugs and Public Policy University of Maryland, Baltimore

2212 S. Park St.

Kalamazoo, MI 49001 pmckerch@aol.com

\section{DISCLOSURES}

Some statistics in this article were discusseed by the author in his presentation, "Consumer Importation of Pharmaceuticals," at the opening general session at the Michigan Pharmacists Association Annual Convention and Exposition, February 19, 2005, Dearborn, MI. He discloses no potential bias or conflict of interest relating to this article.

\section{REFERENCES}

1. National Community Pharmacists Association. 2004 NCPA-Pfizer Digest. October 2004. Available at: www.ncpanet.org. Accessed February 15, 2006.

2. Kaiser Family Foundation. Statehealthfacts.org (your source for state health data). Available at: http://www.statehealthfacts.org/. Accessed January 21, 2005.

3. Novartis. Pharmacy Benefit Report. 2004 ed. Facts \& Figures. East Hanover, NJ: Novartis Pharmaceutical Corporation; 2004.

4. BlueCross, BlueShield, BlueCare Network of Michigan. Fact Book reports 2,333 Michigan pharmacies in 2001 with 2,315 formally participating. Detroit, MI: BlueCross Blue Shield; 2001

5. Milliman USA. Potential cost impact of Michigan House Bills 4987, 5437, and 5438 on purchasers of prescription drug benefits. October 1, 2003. Available at: http://www.pcmanet.org/research/istudies/

MillimanAnalysisofMIBills_4987_. Accessed November 12, 2005

6. House Bill 4987. Available at: http://www.legislature.mi.gov/mileg.asp? page=getObject\&objName=2003-HB-4987. Accessed November 12, 2005.

7. Norris, K. Study says pharmacy laws would add to costs Detroit Free Press. March 23, 2004:1C.

8. Michigan state government Web site. Table 1. Annual estimates of the population for the United States and states, and for Puerto Rico: April 1, 2000, to July 1, 2005. Available at: http://www.michigan.gov/documents/hal_lm_census_ US_States_PR_00_to_05_145527_7.xls. Accessed January 20, 2006.

9. Kaiser Family Foundation. Prescription drug trends. October 2004. Available at: http://www.statehealthfacts.org/. Accessed January 21, 2005.

10. McKinnell H. Call to Action. New York, NY: The McGraw-Hill Companies; 2005:63.

11. Berenson A. Maker of Vioxx reports progress of suits. New York Times. August 26, 2005. Available at: http://www.nytimes.com/2005/08/26/ business/26vioxx.html?ex $=1133586000 \&$ \&en $=$ f8de 3942 be 5 c 843 a \&ei $=5070$ Accessed August 29, 2005.

12. Department of Health and Human Services. HHS Task Force on Drug Importation. December 2004:IX. Available at: http://www.hhs.gov/ importtaskforce/. Accessed August 29, 2005. 


\section{Commentary}

13. IMS Health. IMS country sales report, 2004. Available at: http://www.imshealth.com. Accessed February 15, 2006.

14. Wagenknecht L. Challenges to a border state pharmacy association. Manag Care. 2004;13(3)(suppl):S36-S37.

15. U.S. Congressional Budget Office. Economic and budget issue brief. Would prescription drug importation reduce U.S. drug spending? April 29, 2004. Available at: http://cbo.gov/showdoc.. fm ?index $=5406 \&$ sequence $=0$. Accessed August 29, 2005.
16. Senate Bill 2328. The Pharmaceutical Market Access and Drug Safety Act of 2004. Available at: http://thomas.loc.gov/cgi-bin/query/D?c108:1:./temp/ $\sim$ c108zBVcsg. Accessed November 13, 2005.

17. Carroll NV, Brusilovsky I, York B, Oscar R. Comparison of costs of community and mail service pharmacy. J Am Pharm Assoc. 2005;45(3):336-43.

18. Smith D. Prescription drug importation, investment and employment in Michigan, University of Michigan; August 18, 2004. Available from author at: deans@umich.edu. 